\title{
Gerry LaFemina
}

\section{Fields of Inquiry: Poetic Composition, Revision, and Transcendence}

In the poetry classroom, students often talk about poems in workshop as if they were all nearly finished - as if they were close to publishable. Although this is true in some cases, many of the poems I see on the worksheet are still in their infancy, the writers still working through what they hope to discover. These students will talk about having had an idea for the particular poem, as if poems were based solely on one idea, a preconceived end, which they could see from the starting line at the top of the page. This view of the poem prevents the writer from unfolding the lyricism inherent in the actual writing. Furthermore, this view considers composition as an end, rather than as a means; the best poems, however, lead the writer, and hence the reader, to a visceral experience. Poetry, thought of in this way, considers discovery and the possibilities of new experience as an end for poetry. For example, in the spring of 2003 at a Sarah Lawrence College poetry workshop, student Anna Richey brought this poem to class:

\section{The Shower and the Samurai}

The pipes drone;

as the cold swords

of Samurai hands line up to fight

when I turn the knob

to let the wet gallop

begin: I am a green mountain

in the shower,

under their feet, I splash

soap to their lips

to make them foam

me with anger,

as the dirt of sleep crumbles

into the canyon.

They plunge

deeper, these little kamikazes, rushing to rinse

the sweat, soil, and yeast

with their rain-

drop bodies streaming and fat

with clear blood

flooding the tub 
and the tombs

of this tiled mausoleum. (Richey [Feb 2003])

In general, her classmates liked this poem more than I did. Anna was a senior, and she had written a number of fine poems before this; in fact, she'd written some of the best poems in the class. I should point out right now that if another student - one who wasn't working at the high level Anna had set for herself - had brought this poem in, I may have been delighted by the poem's playfulness and its ability to find new avenues for the metaphor. So I could see much of what her classmates enjoyed about the poem, but I also felt the poem didn't do enough, didn't explore the possibilities deeply enough. My problem, in the end, wasn't the product so much as the compositional method of the poem. I had seen enough poems by Anna at this point to know the poem was only working on one level, whereas her most successful poems worked on several. This is not the sort of constructive criticism one can give the poem if the workshop focuses solely on issues of prosody. Without changing the goals of composition, the class could only impact the final version of this poem cosmetically. Perhaps the line breaks would change, perhaps the slow opening of the poem would disappear; ultimately, however, the poem would not expand beyond its original boundaries with such criticism. Even if we assume that poetry's role is as much linguistic as it is visionary, one way to improve as a writer and thinker is to push the poem beyond its triggering event, to transcend that initiating experience.

Issues of craft aside, therefore, this poem's shortcomings are rooted in its compositional goals: that is, the poet never pushed the poem beyond its opening idea. The poem felt as if Anna came up with this great metaphor in the shower and wrote it down; therefore, the insight - the lyricism, the experience, the energy - occurs off the page. Rather than being a starting point from which poetry happens, the realisation of the metaphor and its linguistic possibilities (that the rain strikes like little aqua-samurai) becomes the sole goal of the poem. A successful poem ought to move beyond this initial moment: a writer needs to be curious, to explore the self/world by pursuing a poem to its end. This is a little moment of transcendence, but an important one.

Poetry - all art, really - isn't about transcription. It's about exploration. It's spelunking in the caves of the unconscious. Basho's narrow road to the interior is as much a travelogue of the experience of travelling into the self as it is of travelling into Japan - the self is transformed by this travel and the travel is influenced by our rationale for the trip. The best poems reach both inward and outward, and they do this by examining any insight the real world gives to us. I often ask students to keep image journals, and we discuss how the images they choose to focus on from their daily lives - and the language they use to capture those images - seem to reflect their internal landscapes (their moods, emotional sensibilities, etc). This insight is the first clue. Poets are detectives who must pursue the leads where the clue takes them - usually to other clues: images, sounds, rhythms, ideas, language play, memories, fictions. These are the syntactical and cognitive leaps that Bly begs for in his seminal Leaping Poetry. These are the things that make poetry a kind of 'prayer', an attempt, as it were, to connect with what is beyond purely empirical experience.

Art, physics, religion, philosophy - all these things are a possible means for transcendence. They can be a means to a greater end for both the maker and audience. They are ways of delving into the dual realms of the physical and metaphysical. Done fully, such exploration may put the self - 
as a consciousness - at stake. I do not mean revealing autobiographical facts; one would hope that we are more than the sum of our experiences, and even the so-called confessional poets crafted their sense of autobiography to be more than historical facts; rather, by risking something, I mean exposing the mind as a seeker of the beyond-self through the making/experience of art. Even the descriptive poem begs us to ask - why this item, what fresh insight do we get from re-envisioning this thing through this lens? The question for the writer becomes: what is that something for you as a writer? Whether the poet uses experimental forms or linguistic play, or uses the poem as a contemplative rhetorical device, poetry ought to challenge the self. In the end, if we are to avoid the bogeyman of the 'workshop poem', then we have to ask our students to write beyond the merely anecdotal and finely wrought, but easy, product. Such challenge makes the poem an intimate experience of language for readers. How did writing this poem challenge you? is a question I often ask my students. I might as well be asking: Where's this poem's duende?

Thought of this way then, the blank page, the canvas, the whiteboard of the physicist, all become fields of inquiry; that which we write becomes the mode of inquiry, the means to discover what the self doesn't know it knows. William Stafford once said that he never preconceives what he's going to write - rather, he looks out of the window and jots down what he sees and lets that lead him into the realm of the imaginative, the unconscious and the conscious minds. The poem/artwork/philosophical treatise/song/what-have-you becomes a nexus of those minds at that moment. It's a fleeting sort of transcendence however, one the artwork itself attempts to make permanent.

It is this movement toward discovery, toward the transcendent, toward the beyond-self, that I mean by the word 'prayer' - rather than any prescriptive understanding of the term in Judaeo-Christian connotation; I was hoping for a sensibility similar to that of those ancient poets who tried to answer questions about the physical world through the making of metaphysical constructs in poetry. Contemporary poets now often make metaphysical constructs to understand their own experience, leaving the physical world to the physicists. The desire to ask existential questions, to attempt to rewrite (or repaint, retheorise, etc) the world in another manner is one possible manifestation to this type of prayer. Schools of art, trends in writing, allow artists of a certain era to form communities that discuss the possibilities in similar fashion through interpretations of a particular sensibility. Thus Dada (which few at the time would have considered a sort of prayer), performance art, poetry and painting - all try to answer particular questions through a variety of mediums via personal interpretations of a school of thought. In the creative writing classroom, students ought to feel part of such a community when we encourage them to push each other toward creative milestones. These milestones should be an easy measure of success for them as, at their level of experience, such advances in the relationship to craft and content, voice and vision ought to come more quickly.

After his discussion of Gide's sense of the novel, EM Forster mentions an old woman accused of being illogical who says: 'Logic, what rubbish! How can I know what I think till I see what I say' (Forster 1954: 152). Poetry is one way for us to understand how we think, what we believe, how we feel. And sometimes it surprises us. Again as Forster notes, 'there is a vague and vast residue into which the subconscious enters[:] Poetry, religion, passion ...' (1954: 154). 
But poets/artists all have unique personalities, and a unique set of experiences from which to mine. As class discussion pursued this track, Anna asked me about Charles Simic's 'Watermelons':

\author{
Green Buddhas \\ on the fruit stand \\ We eat the smiles \\ and spit out the teeth. (Simic 1990: 61)
}

Simic once said in an interview that his early poems were an attempt to rediscover the childlike awe one has with the world. He would take common objects and just write, allowing his mind to play on the objects as he wrote, in order to find something new about them. It seems that Simic was in search of the spark of god that ancient Talmudic scholars believed was in every aspect of creation. This was Simic's personal sensibility. Although purely descriptive, the freshness of the image, and the surprising leap between the subject (watermelons) and the metaphor (green Buddhas), give the poem energy. If one imagines how students might reinvent emotions they've had with fresh objective correlatives (using an image journals or other exercises), one begins to see the possibility for cognitive leaps. When the reader shares such a leap with a writer, the reader and writer 'travel' together, and thus transcend the boundaries of personal experience.

Still, each artist must hammer out his or her own artistic sensibility. Barbara Hurd notes in her essay on the role of chaos in the creative process, 'Finding and Making: The Strange Attractor's Contributor to Form', the difference between her attempts at working with metal while at the Haystack Artist Colony, as opposed to that of the metalworkers:

I might have had plenty of action in the metal studio, a busy wrist and forearm and hand clenched tight around a tool, but I had no sensitivity to metal. I didn't know how brass might be altered, what kind of pressure makes it move in what kinds of ways ... I just banged it blindly. ... The beginner, with luck, bangs a little less blindly each day. $\mathrm{He} / \mathrm{she}$ has a greater sense of what the material might yield and of some governing design. Somewhere between the two is, perhaps, where discovery resides.(Hurd [April 2006])

As teachers, we're trying to show students how language can be bent and shaped. And that means training a student's sensitivity to language. Through the process of writing revisions, we hope our students learn what language 'might yield'. We must beg our students to use the process of writing to discover their own artistic sensibility by giving them models of what's possible, but also urge them to learn what's possible through their own processes.

As a student at Sarah Lawrence in the eighties, I often found myself trying to write poems under the influence of one of my earliest teachers, Thomas Lux. I would come up with ideas for Lux-esque poems and write them. The ideas happened before the poems. The final products may have been well crafted (or not), but they seemed tedious. They didn't dig into the material of poetry essential to my being a poet because Lux was doing something I didn't then understand, and thus my poems were, ultimately, necessary failures. Necessary for me to learn about craft and to learn what I wanted and didn't want a poem to do. As a teacher I find myself walking 
the tightrope between poems that succeed on the levels of pure prosody and poems that succeed on some deeper level, poems that have what Federico Garcia Lorca dubbed duende.

Thought about this way, a poem is an access hatch to understanding, not a servant to it. Once you say I'm going to write about how I'm victimized, or how I was molested, or how much I love raisins, or how raisins alone are like my grandfather's knuckles, you shut down the possibilities of the field of inquiry. You ask the poem to not open doors. You say: 'don't surprise me.' The best poems about one's own pain are written when one doesn't expect to write about it. Where does 'his knuckles like raisins' take you? For instance, a few years back I wrote a poem called 'The Sound a Body Makes'. When I began it, I had no idea what it was going to be about - I just had the opening line : 'Only three days later, I realized, the chalk outline was gone'. What is this? I wondered as I wrote it down. A persona piece? A prose poem's opening? I had no idea. As I followed the thread of the poem, I was surprised to learn I was writing about something I hadn't thought about in years - having the body of a suicide land four feet in front of me one afternoon when I was 16 . The poem goes on from there to surprise me even more. 'Even I had flinched in the hot breath of an approaching subway,' I wrote. Where did that come from? I had no clue, but I was trying to make a connection to the jumper, trying to generate empathy, which for me is what I want my poems to do. I don't think about this consciously when I write, but I think my poems are most successful when they attempt this.

I am not saying one should declare: this is my poetic enterprise and all my poems should be in service to it because that's just as prescriptive as my previous concerns, and thus could equally prevent a poet from evolving; instead, I suggest encouraging students to find a set of formal concerns, and a desire to be awed that allow each one's poetic enterprise to come out. Encourage that they find a voice that is as much a part of one's compositional goals as vision. Jack Ridl describes his mission as a teacher as two-fold, both having to do with this pedagogical sensibility:

1. To be alert for signs of a student's moving toward her/his own vision, to be very careful not to destroy it simply because I think 'she/he can't live without also ...' and to support the authenticity of the vision.

2. To give the students the elements that go into making any poem (image, rhythm, line, that stuff) and show them that these are not mere decor, or craft, but a key means by which their work is transformed into art, that are to be reconsidered for each poem, that one never learns how to write poetry, that one must always be willing to learn how to write the next poem. (Ridl 2004)

In other words, poets have to take the triggering event and transform it (transcend it) into art, and often students haven't done that yet, and often they have no experience doing it. Early on we need to encourage them to find a vision. In order to illustrate for students that the poem is a nexus of voice, vision and craft, and that it is also the place through which these things evolve, I had my Sarah Lawrence students do conference projects in which they looked at the work of one poet throughout his/her career in order to see such development. A careful reader can see what obsesses a poet through the body of work; ditto one can see how the possibilities of poetry evolve for the poet in order to help open up those inquiries. Lastly, new vision and new voice require a different approach to craft. 
I have also used anthologies such as Parini and Pack's Introspections, which focus on one poem by a variety of poets and which includes essays about the crafting of each poem - often including drafts of the work, the writer's initial concerns, and an understanding of the poem as crafted into something more than its initial language and event. When visiting writers come to the university, their classroom discussion usually includes a walkthrough of the revision process, the goal of which is to show students that the best poems often push beyond their triggering concerns.

In speaking about the work of Matisse, Kandinsky said:

He paints 'pictures', and in these 'pictures' endeavors to reproduce the divine. To attain this end he requires as a starting point nothing but the object to be painted (human being or whatever it may be), and then the methods that belong to painting alone. (Kandinsky 1977: 18)

Early on in the poetry classroom, I try to help my students attain the methods that belong to prosody alone; students are often given a variety of prompts to help find the 'objects' of their poems. But the third thing an artist needs, Kandinsky seems to imply, is a vision of the divine. One can't give a student that vision, of course; one can encourage a student to dig beyond the superficial, the first thought, the closed metaphor, the closed linguistic door. We have to teach process by pushing our students to keep searching. That's not always easy in a culture that values product first.

One of the risks all successful artists take - even ones working in the rather non-lucrative medium of poetry - is the risk of commodification of their art work. When one has to paint several paintings a year just like the successful one in order to make sales, or to match past successes. Are the later 'Dream Songs' of Berryman better, more successful, or any more revelatory than the first ones? No. Marvin Bell's Book of the Deadman kept me turning pages; much of Ardor, the second book of the deadman, left me feeling like I'd been there, done that. And it's sad for me to admit that the awe I used to feel reading Simic has been lessened by the seemingly more-formulaic work he is writing these days, no less a formula than that of the new formalists who tried to convince us that fixed form and fixed form alone could make better poems in workshop. In Anna's case her success in the class to that time made it clear her poem could have been more. A poem can't open outward - can't flower, if you will - in service to any preconceived formula, whether it be an agenda, a controlling metaphor, or form alone. Ditto it can't succeed if it only stays on square one. These things may be part of the process, but the artist must also surrender control to the process. It's a difficult thing to teach, but looking as work by poets through a variety of career stages can help.

Adrienne Rich's more recent works exemplify the evolution of vision and prosody moving in synch; her poems have grown beyond sole service to an agenda. Her beliefs, her choices, her selfhood will always be in her poems because they are part of who she is - they don't need to be consciously placed there; in her more recent poems (An Atlas of the Difficult World, Midnight Salvage, and Fox) the socio-political agenda works as an underlying sensibility in the poems rather than as the main player. This shift in focus has given her poems more layers on which to work, more subtlety and grace, and therefore more powerful impact.

One can't help but allow one's obsessions entry into poems, but poems - to be realized fully - have to go beyond such service to the self. When poems 
are put in the service of the self's conscious decisions alone, the poem is cut off from the limitless possibility the blank page allows - that field of inquiry that should allow us to say: I always do this when I write a poem, what if I do something different. Access to a Zen state, or Jungian universal unconsciousness, or Christian Mysticism, or the athlete's 'zone' is achieved through process. At its highest level it is both a type of prayer and a type of exploration.

Of course, this means risking failure. Spelunking the depths of limitless possibility and potentiality means one can get lost in the cave. But the search for something beyond the self is worth the risk. An old circus aerialist once told me, 'The tricks are nothing with a net. Life is nothing with a net'. This is what I meant most by writing poems that take risks ones that begin without a preconceived notion. The notion is the net.

When I think of Anna's poem again and wonder how that poem led me to this tangent to begin with, I think I know. The poem's idea was clever. So much possibility, so much fertile ground lay around the initial idea, I wanted her to go out and explore it even if she wrote a less 'successfully' crafted poem, because what the poem may have achieved would have been worth the risk. In her final portfolio, Anna tried working with the poem in a new draft:

\section{After waking to an alarmful of war}

My naked body drones with its pit full of war stories that have flooded the last of my sleep, but with dusty eyes I turn on the knob to let a wet gallop begin: I think I am a green mountain

in the shower, under the soaking feet of warriors. I splash soap to their lips to make them foam me with anger as the dirt of my sleep crumbles into the canyon. They plunge

deeper into my skin and risk slipping into the suck of death: Can these drops

be little kamikazes?

Who rush to rinse my world in a war of routine - they are older than bloodshed.

Their rain-

drop bodies stream fat like Samurai with clear blood that floods the tub and the tombs of this tiled mausoleum.

The mud lump they have made me might not be cleansed unless.... I think of a better ending to this poem. (Sorry still can't think of one) (Richey [May 2003]) 
Here Anna has tried to do something differently. Part of the transformation is in the title, which allows the outside world into the poem. Written during the build up to the War in Iraq, the writer's dread begins to come into play from the opening, which makes it clear the speaker has been listening to war news on the radio as she was waking. Thus the original preconceived realization has found a new connection - a connection to world affairs, which is played out even more effectively in her use of the free verse line (ie 'My world in a war'). She has also risked something, tried stretching beyond what she originally knew. In this case, she still hasn't found a way to make another leap, to take the speaker-self and reader into the deep end, so the poem peters out, and that's okay. Just as athletes practice to get into the zone or theoretical physicists use computer algorithms to test calculations, so too do writers make revisions. The workshop is the place to test those attempts; therefore, its participants need to be rigorous and demanding, focusing on re-visioning the poem (literally seeing it new) rather than just issues of prosody and ordering.

Composition is not a one-time event; revision helps us hone our thoughts/perceptions/feelings and enables us to explore ideas more fully, give moments greater lyricism. Furthermore, done well - done with an emphasis on craft - this process embodies and expands student curiosity about the world, themselves, and the art form. This prepares them for the composition, prepares us for the deeper cave to explore, the fleeting nirvana that is our next best poem. Anna has been forced to pursue where her poem will take her, and in this way she is discovering more about herself, the world, and how her poetry is the imaginative intersection where the two meet. My job as mentor is to point this out to her, and to teach her the prosody that enables this to happen. It is through this engagement that real poetry surfaces. In this way the poet is a maker/creator - not just of the poems, but of the poet as something more than the self, of self-plus-the-experience-of-writing-the-poem. We, as writers, are transformed by our discoveries, and if so, we hope the reader will be equally transformed.

\section{Works cited}

Bly, Robert 1975 Leaping poetry, Boston: Beacon Press Return to text

Forster, EM 1954 Aspects of the Novel, New York: Harcourt, Brace \& World Return to text

Hurd, Barbara [April 2006] 'Finding and making: The strange attractor's contributor to form' (published with permission) Return to text

Kandinsky, Wassily 1977 Concerning the spiritual in art (trans MTH Sadler), New York: Dover Return to text

Parini, Jay and Robert Pack (eds) 1998 Introspections: American Poets on One of Their Own Poems, Lebanon, NH: University Press of New England Return to text

Richey, Anna [May 2003] 'After Waking Up to an Alarmful of War' (published with permission) Return to text

Richey, Anna [Feb 2003] 'The Shower and the Samurai' (published with permission) Return to text

Ridl, Jack 2004 Personal correspondence, 4 June Return to text

Simic, Charles 1985 The uncertain certainty, Ann Arbor: U Michigan Press 
Simic, Charles 1990 Selected poems 1963-1983 (revised and expanded), New York: George Brazillier Return to text

Stafford, William 1978 'A way of writing' in Writing the Australian crawl, Ann Arbor: U Michigan Press, 17-20 Return to text

Gerry LaFemina's books include The Parakeets of Brooklyn (2005), which was published in a bilingual edition of English and Italian, The Window Facing Winter, and Zarathustra in Love, a collection of prose poems. A former board member of the Association of Writers and Writing Programs (AWP), he directs the Frostburg Center for Creative Writing at Frostburg State University, where he also teaches.

\section{TEXT}

Vol 10 No 2 October 2006

http://www.griffith.edu.au/school/art/text/

Editors: Nigel Krauth \& Jen Webb

Text@griffith.edu.au 